\title{
Evolution of perturbations in 3D air quality models
}

\author{
Ioannis Kioutsioukis $\left({ }^{1}\right)\left({ }^{2}\right)$, Christos Zerefos $\left({ }^{2}\right)$, Dimitrios Melas $\left({ }^{2}\right)$ and Ioannis Ziomas $\left({ }^{2}\right)$ \\ $\left({ }^{1}\right)$ European Commission, Joint research Centre, Institute for the \\ Protection and Security of the Citizen, Ispra (VA), Italy \\ $\left(^{2}\right)$ Aristotle University of Thessaloniki, Laboratory of Atmospheric Physics, Thessaloniki, Greece
}

\begin{abstract}
The deterministic approach of sensitivity analysis is applied on the solution vector of an Air Quality Model. In particular, the photochemical CAMx code is augmented with derivatives utilising the automatic differentiation software ADIFOR. The enhanced with derivatives version of the model is then adopted in a study of the effect of perturbations at the boundary conditions on the predicted ozone concentrations. The calculated derivative matrix provides valuable information e.g., on the ordering of the influential factors or the localisation of highly affected regions. Two fundamentally different domains of the Auto-Oil II programme were used as test cases for the simulations, namely Athens and Milan. The results suggest that ozone concentration be highly affected by its own boundary conditions and subsequently, with an order of magnitude less, by the boundary conditions of NOX and VOC.
\end{abstract}

Key words perturbation growth - automatic differentiation - three-dimensional numerical models sensitivity analysis - air quality models

\section{Introduction}

A photochemical Air Quality Models (PAQM) utilises meteorology, air quality, terrain and emissions data and a chemical mechanism and simulates the concentration of chemical species in each cell of a 3D grid. The overall modelling procedure has an inherent stochasticity arising from either the simplification of the various processes or the data estimates. However, comprehensive sensitivity analysis of 3-Dimensional (3D) PAQM does not exist, mainly because of the associated computational cost, human effort and data needs (Peters et al., 1995; Carmichael et al., 1997; Pielke, 1998).

Mailing address: Dr. Ioannis Kioutsioukis, European Commission, Joint Research Centre, Institute for the Protection and Security of the Citizen, T.P. 361, Via E. Fermi 1, 21020 Ispra (VA), Italy; e-mail: ioannis.kioutsioukis@jrc.it
Sensitivity analysis methods are generally grouped as deterministic (local) or statistical (global). Most of them can be seen as a derivative estimation problem. The enhancement of a computer code with derivatives can be made through four different techniques (Bischof, 1994) including «divided differences» or «symbolic differentiation». However, for a computer code of roughly 40000 lines, the applicability of those techniques is limited. Recently, a new technique called Automatic Differentiation (AD) (Rall, 1981; Griewank, 1989; Griewank, 2000) became available which augments a computer code with derivatives in a completely mechanical way. The technique requires minor modifications of the original code and inserts new lines of code in original program that account for the differentiation of the dependent parameters with respect to the independent ones. The accuracy of the AD-calculated derivatives has been demonstrated in several studies (Bischof et al., 1992; Horwedel et al., 1992; Park and Droegemeier, 1999; Kioutsioukis and Skouloudis, 2001; among others).This study examines the robustness of a model's predictions 
to perturbations. In particular, the photochemical CAMx (Comprehensive Air Quality Model with eXtensions) code (Environ, 1998) is augmented with derivatives utilising the automatic differentiation software ADIFOR (Automatic Diferrentiation in FORtran) (Bischof et al., 1996). The enhanced with derivatives version of the model is then adopted in a study of the effect of perturbations at the boundary conditions on the predicted ozone concentrations. Two Auto-Oil II domains including the cities of Athens and Milan respectively were selected as test cases.

\section{Methodology}

Automatic differentiation tools apply the chain rule systematically to elementary operations and functions to generate derivative codes - either Tangent Linear Model (TLM) or adjoint model (ADJM) - of nonlinear models (Bischof et al., 1992). The TLM describes the linearised evolution of errors or perturbations about the trajectory of some particular reference solution (Bischof, 1994). Its name is derived from the fact that a solution to the TLM always falls somewhere on the instantaneous tangent to the reference solution as both of them evolve in time. Furthermore, it can be shown that: a) the first order perturbation of any prognostic or diagnostic variable may be obtained by evaluating the derivative of that variable with respect to the perturbation parameter, and b) the sensitivity is a property of the unperturbed trajectory.

The ADIFOR tool generates a tangent linear code that computes the sensitivities (first-order partial derivatives in the Taylor expansion) of all dependent variables with respect to all independent variables for a single run. A single run of the ADIFOR-generated derivative code is equivalent to as many tangent linear model runs as the number of independent variables (i.e., multiple sensitivities can be calculated simultaneously and independently).

Consider we perturb the boundary concentration of a chemical specie $j$ by a factor $e_{j}$ (Kioutsioukis and Skouloudis, 2001)

$$
C_{B N D^{j}}\left(x, y, x, t, e_{j}\right)=\left(1+e_{j}\right) C_{B N D^{j}}(x, y, x, t)
$$

and afterwards we expand $C_{i}\left(e_{j}\right)$ in a Taylor Series about the reference solution $\left[C_{i}\left(e_{j}=0\right)\right]$. If the concentration of a specie $i, C_{i}$, is affected by the boundary concentration of the specie $j$, it implicitly depends upon $e_{j}$. Therefore, the linear estimation of the change in concentration $C_{i}$ that originates from a unitary and uniform perturbation in variable $e_{i}$ is estimated through sensitivity coefficient (Saltelli et al., 2000)

$$
S_{1}^{i j}=\frac{\partial C_{i}}{\partial e_{j}}
$$

$S_{1}$ is a dimensional quantity and provides information on the absolute importance of input parameters on the sensitivity fields. In our experiment, we will use the normalised $S_{1}$, which is $S_{1}$ divided by the boundary concentration of the investigated chemical compound. Its value measures the change in $C_{i}(\mathrm{ppb})$ that originates from $1 \mathrm{ppb}$ change in the boundary conditions of $j$ ( $\mathrm{ppb}=$ part per billion).

\section{Results and discussion}

\subsection{Model setup}

The selected domains for this application were two out of eleven cities of the Auto-Oil II Programme (http://europa.eu.int/comm/ environment/autooil.index.htm). The first domain, containing the city of Athens (e.g., Ziomas et al., 1998), is a very inhomogeneous domain including half sea and half continent with steep topography. The computational domain is $300 \times 282 \times 2 \mathrm{~km}^{3}$ with the south-west corner of the coarse and fine grid at $(21.9 \mathrm{E}, 36.6 \mathrm{~N})$ and $(23.1 \mathrm{E}, 37.5 \mathrm{~N})$ respectively. The simulation day was the 28th July 1995 . The maximum surface wind speed and temperature was $11-13 \mathrm{~m} / \mathrm{s}$ and $36.4^{\circ} \mathrm{C}$ (no precipitation). The second domain is also a challenging one. It contains the city of Milan (e.g., Silibello et al., 1998) as well as the cities of Genoa and Bologna close to the boundaries. In the north and west boundary we find the Alps while the rest of the domain is almost flat (Po valley). This modelling domain is $258 \times 276 \times 2 \mathrm{~km}^{3}$ with the south-west corner of the coarse grid at $(8.1 \mathrm{E}, 43.8 \mathrm{~N})$ and of the fine 

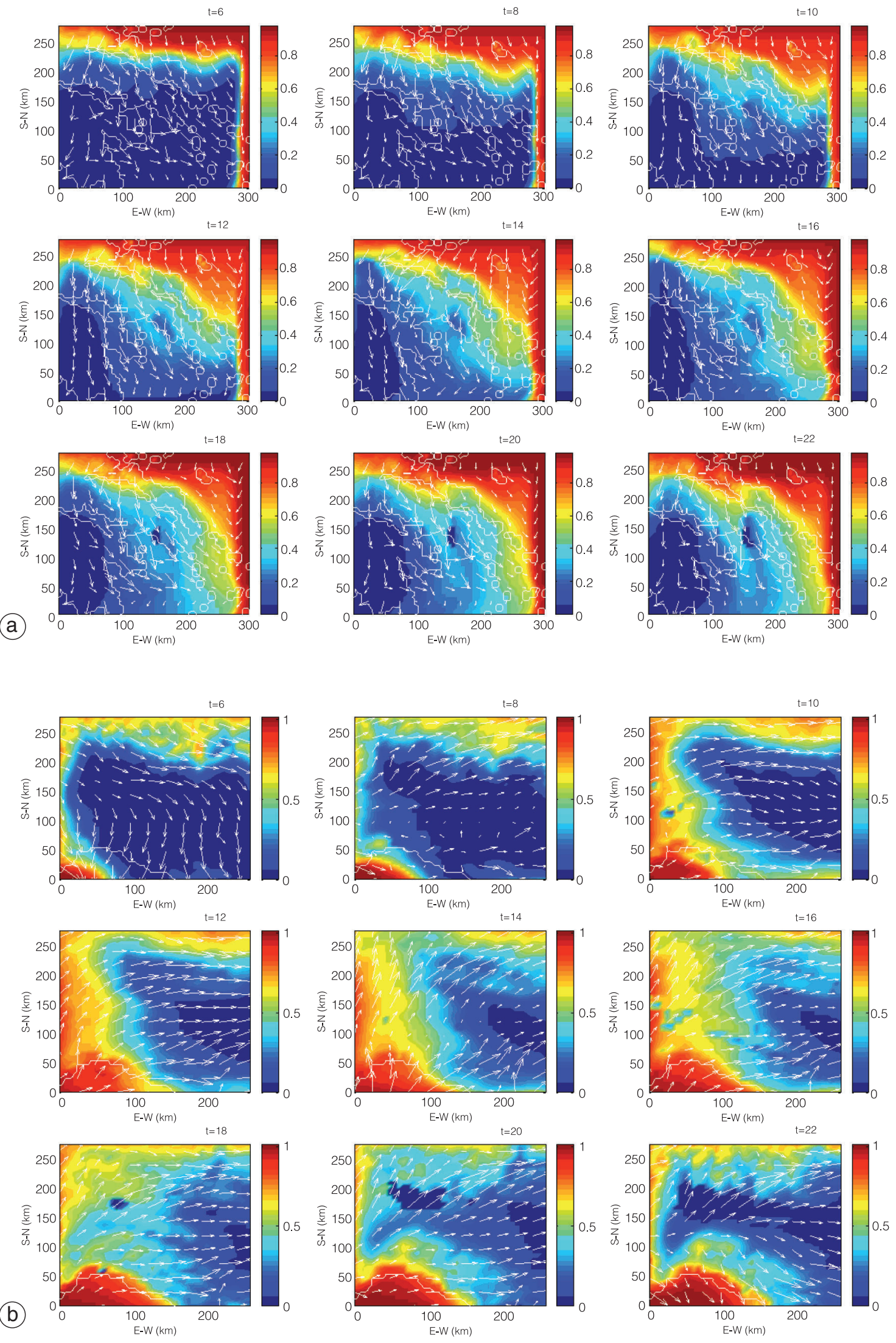

Fig. 1a,b. Evolution of $S_{1}^{03}{ }^{03}$ for the domain of: a) Athens; b) Milan. 
grid at $(8.7 \mathrm{E}, 45 \mathrm{~N})$. The simulation day was the 6 th May 1995. Maximum surface wind speed and temperature in the domain were less than $11 \mathrm{~m} / \mathrm{s}$ and $29.5^{\circ} \mathrm{C}$ (no precipitation) respectively.

CAMx (Environ, 1998) is a Eulerian photochemical grid model that enables the integrated assessment of gaseous and particulate airpollution over many scales, from individual point source impacts to urban-regional effects. CAMx simulates the emission, dispersion and removal of inert and chemically reactive pollutants in the lower troposphere by solving the pollutant continuity equation for each chemical compound on a system of nested three-dimensional grids. The inputs of the model used were:

- 13 vertical layers, from $20 \mathrm{~m}$ up to $2000 \mathrm{~m}$.

- 6/2 km horizontal spacing for coarse/fine grid.

- Carbon Bond IV chemical mechanism (Gery et al., 1989).

- Boundary conditions: $1 \mathrm{ppb}$ for $\mathrm{NO}_{\mathrm{x}}, 15.5$ $\mathrm{ppbC}$ for $\mathrm{VOC}, 60 \mathrm{ppb}$ for $\mathrm{O}_{3}$ and $300 \mathrm{ppb}$ for $\mathrm{CO}$.

- Meteorological fields were provided by simulations of the Advanced Regional Prediction System (ARPS) (Xue et al., 2000).

\subsection{Sensitivity to the boundary conditions}

Figure 1 (a: Athens, b: Milan) illustrates the general features of the evolution of $\mathrm{O}_{3}$ sensitivity (from 06:00 LST up to 22:00 LST) for perturbations in $\mathrm{O}_{3}$ (in our simulations, the boundary conditions were continuously perturbed; that is, the sensitivity coefficients at 14:00 correspond to the effect of perturbed boundary conditions until that time). Similarly, in figs. $2 a, b, 3 a, b$ and $4 a, b$ is shown the local sensitivity of $\mathrm{O}_{3}$ arising from perturbations in $\mathrm{NO}_{x}$, VOC and $\mathrm{CO}$ respectively. Among all perturbations, the largest sensitivity in $\mathrm{O}_{3}$ is due to the $e_{\mathrm{O}}$ perturbation, followed by $e_{\mathrm{Nox}}$. We note that:

- The perturbations in $\mathrm{O}_{3}$ boundary conditions lead to net $\mathrm{O}_{3}$ transport inside the domain. The magnitude of this perturbation is decreasing downwind the boundaries. However, the actual local enhancement in $\mathrm{O}_{3}$ concentration depends mainly on the ratio among its precursors. In areas with a low $\mathrm{H}_{2} \mathrm{O}_{2} / \mathrm{HNO}_{3}$ ratio (e.g., city centres) the additional $\mathrm{O}_{3}$ reacts with the $\mathrm{NO}_{\mathrm{X}}$, and thus the perturbation effect is smaller. We see this discontinuity in the $\mathrm{S}_{1}{ }^{03}$.3 field in the area of the city centres implying that the high $\mathrm{NO}_{\mathrm{x}}$ emissions there destroy a big part of the transported $\mathrm{O}_{3}$. Finally, the maximum $S_{1}{ }^{0303}$ (fig. 1a,b) is around 1.0 (i.e., $1 \mathrm{ppb}$ perturbation in the boundary conditions of $\mathrm{O}_{3}$ will result in $1 \mathrm{ppb} \mathrm{O}_{3}$ enhancement in some grid points).

- The perturbations at the boundary conditions of $\mathrm{NO}_{\mathrm{x}}$ are advected downwind of the boundaries and result in $\mathrm{O}_{3}$ production in $\mathrm{NO}_{x}$-sensitive areas (areas with a high $\mathrm{H}_{2} \mathrm{O}_{2} / \mathrm{HNO}_{3}$ ratio are characterised as relatively low- $\mathrm{NO}_{\mathrm{x}}$ areas, where we expect high $\mathrm{O}_{3}$ enhancement). The maximum sensitivity from $\mathrm{NO}_{\mathrm{x}}$ is greater than 1.0.

- Similarly, a perturbation at the boundary conditions of VOC and CO that is transported downwind of the boundaries is expected to enhance $\mathrm{O}_{3}$ production in areas with low ratio $\mathrm{VOC} / \mathrm{NO}_{\mathrm{x}}$ (e.g., downwind the city plumes). The maximum sensitivity from VOC was $\sim 0.2$ in Athens and 0.4 in Milan.

- Unlike $S_{1}{ }^{0303}$ whose value is almost constant over time, the $S_{1}{ }^{\text {3 }}$ Nox,$S_{1}{ }^{03} \mathrm{VOC}$ and $S_{1}{ }^{\text {O3 CO }}$ show a diurnal variation. The main reason is that in the first case advection dominates while the second is driven by photochemistry.

- Although the coefficient values show higher sensitivity to $\mathrm{NO}_{\mathrm{x}}$, one should take into account that: a) typical error range for the boundary conditions of $\mathrm{O}_{3}, \mathrm{NO}_{x}$, VOC are in the order of 20,1,10 ppb respectively, and b) typical (clean) boundary conditions in an PAQM are approximately $50 \mathrm{ppb}$ for $\mathrm{O}_{3}, 1 \mathrm{ppb}$ for $\mathrm{NO}_{\mathrm{x}}$ and $10 \mathrm{ppb}$ for VOC. Therefore, in percentages, $1 \mathrm{ppb}$ perturbation is equivalent to $2 \%$ for $\mathrm{O}_{3}, 100 \%$ for $\mathrm{NO}_{\mathrm{x}}$ and $10 \%$ for VOC.

Figure 5 illustrates the cumulative probability of $S_{1}{ }^{\text {o } j}\left(j=\mathrm{O}_{3}, \mathrm{VOC}, \mathrm{NO}_{\mathrm{x}}\right)$ coefficients for the nested fine grids that contain the city centres. The fine grids had their centres in the cities of Athens and Milan and were covering an area of $13608 \mathrm{~km}^{2}$ and $10944 \mathrm{~km}^{2}$ respectively. The local change in $\mathrm{O}_{3}$ arising from perturbations on its own boundary conditions is $0.32 \pm 0.11$ (mean value \pm standard deviation) for Athens. The result for Milan is $0.54 \pm 0$.12. The higher mean value for Milan is due to the closer distance from the boundaries. The perturbation in $\mathrm{NO}_{\mathrm{x}}$ is forecast- 

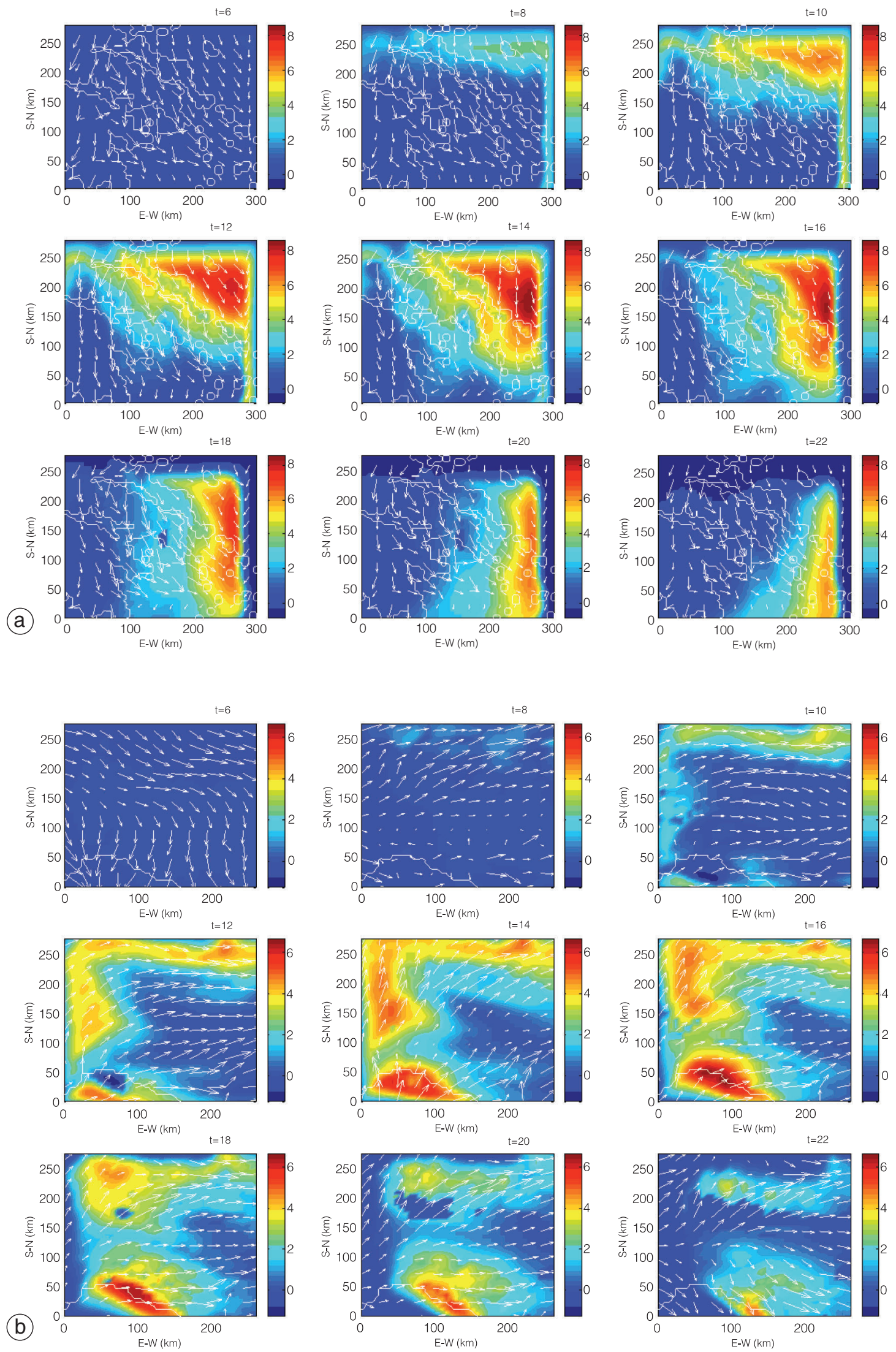

Fig. 2a,b. Evolution of $S_{1}{ }^{\text {03 }}{ }^{\mathrm{NOX}}$ for the domain of: a) Athens; b) Milan. 

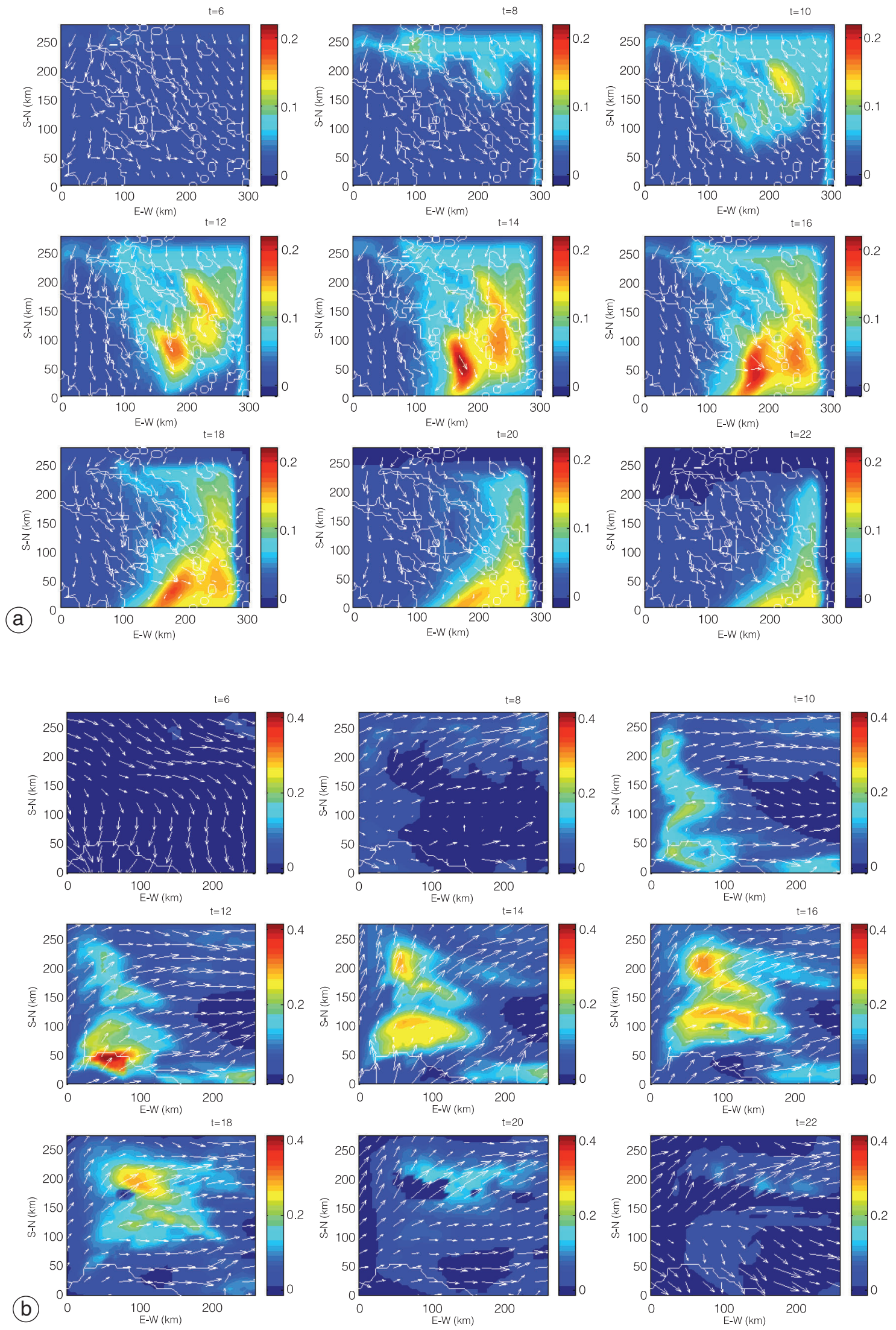

Fig. 3a,b. Evolution of $S_{1}{ }^{\text {03 voc }}$ for the domain of: a) Athens; b) Milan. 

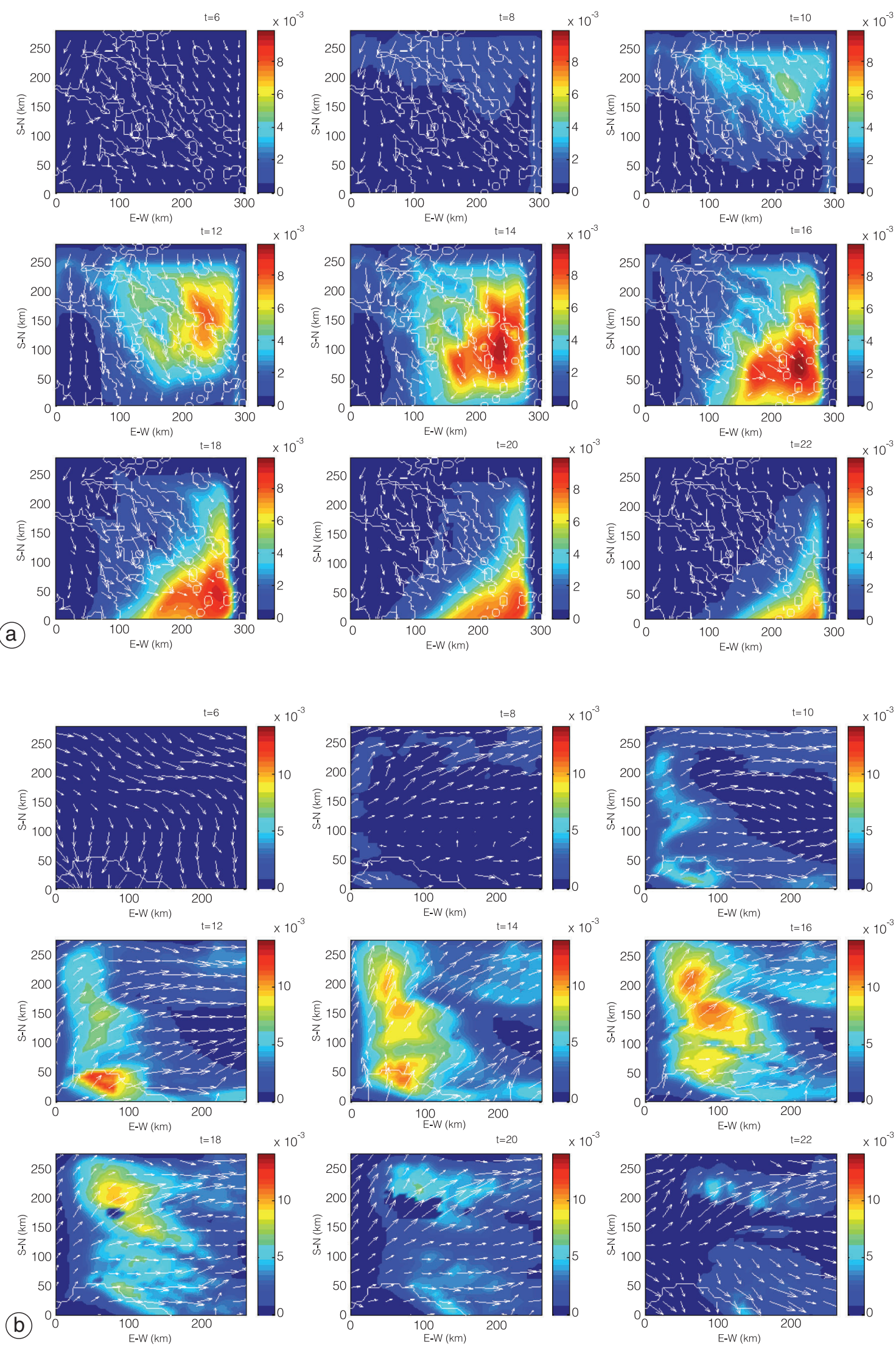

Fig. 4a,b. Evolution of $S_{1}{ }^{\mathrm{O} 3 \mathrm{CO}}$ for the domain of: a) Athens; b) Milan. 

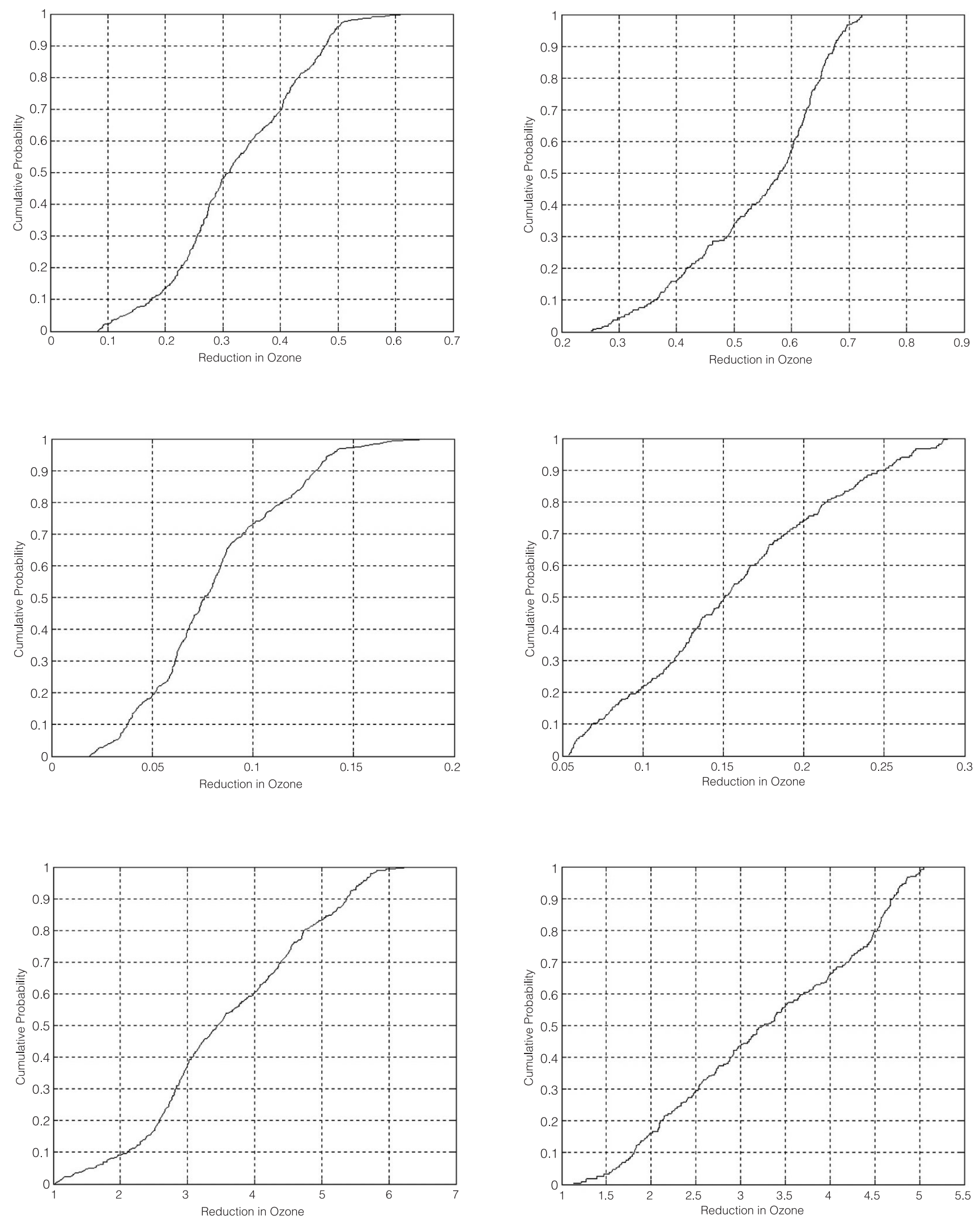

Fig. 5. Cumulative frequency of $S_{1}{ }^{\mathrm{O} j \mathrm{j}}\left(j=\mathrm{O}_{3}, \mathrm{NO}_{\mathrm{x}}\right.$, VOC) at the time of the observed $\mathrm{O}_{3}^{\mathrm{MAX}}$, for perturbations at the boundary conditions of $\mathrm{O}_{3}(t o p)$, VOC (middle) and $\mathrm{NO}_{\mathrm{x}}$ (bottom), for Athens (left) and Milan (right). 
ed to affect $\mathrm{O}_{3}$ by $3.61 \pm 1.23$ in Athens and $3.29 \pm 1.02$ in Milan while the perturbations in VOC vary $\mathrm{O}_{3}$ in Athens by $0.08 \pm 0.03$ (VOC) and in Milan by $0.16 \pm 0.06$ (VOC).

\section{Conclusions}

Sensitivity analysis of 3D PAQM is a field of great importance. However, the associated computational cost has made this task not a trivial one. In this study, we applied a general approach that in only one execution of a PAQM can provide the sensitivities of all output parameters with respect to all its inputs. As an example, we studied the evolution of sensitivity fields for perturbations at the boundary conditions. Finally, we computed the absolute importance of the most important perturbations in the $\mathrm{O}_{3}$ field.

Our results suggest that even with small errors in measured or estimated boundary concentrations of $\mathrm{O}_{3}$, the maximum change in $\mathrm{O}_{3}$ concentrations predicted by a numerical model can be significant. For example, a perturbation of $20 \mathrm{ppb}$ in the boundary conditions of $\mathrm{O}_{3}$ in the domain of Milan will result in $10.8 \pm 2.4$ (ppb) concentration change of $\mathrm{O}_{3}$ in the greater Milan area.

\section{REFERENCES}

Bischof, C. (1994): Automatic Differentiation, Tangent Linear Models and Pseudo-Adjoints, High-Performance Computing in the Geosciences (Kluwer Academic Publishers), 462, 59-80.

Bischof, C., A. Carle, G. Corliss, A. Griewank and P. HOVLAND (1992): ADIFOR - Generating derivative codes from Fortran programs, Scientific Programming, 1, 11-29.

Bischof, C., P. Khademi, A. Mauer and A. CARLE (1996): ADIFOR 2.0 - automatic differentiation of Fortran 77 programs, IEEE Comput. Sci. Eng., 3, 18-32.

CArmichael, G.R., A. SANDU and F.A. Potra (1997): Sensitivity analysis for atmospheric chemistry models via automatic differentiation, Atmos. Environ., 31,
475-489.

ENVIRON (1998): User's guide for CAMX 2.0, pp. 123.

GERY, M.W., G.Z. WhitTEN, J.P. KILlus and M.C. DODGE (1989): A photochemical kinetics mechanism for urban and regional scale computer modelling, J. Geophys. Res., 94, 925-956.

Griewank, A. (1989): On Automatic Differentiation, Mathematical Programming: Recent Developments and Applications (Kluwer Academic Press), 83-108.

Griewank, A. (2000): Automatic Differentiation of Algorithms: Theory, Implementation and Application, SIAM, pp. 353.

Horwedel, J., R. RARIDON and R. Wright (1992): Automated sensitivity analysis of an atmospheric dispersion model, Atmos. Environ., 26A, 1643-1649.

KIOUTSIOUKIS, I. and A.N. SKOULOUDIS (2001): Sensitivity analysis of nested photochemical simulations, in International Technical Meeting on Air Pollution Modelling and its Applications, 15-19 October 2001, Louvain-la-Neuve, Belgium (Kluwer Academic/Plenum Publishers), 337-345 (with discussion).

PARK, S.K. and K.K. DROEGEMEIER (1999): Sensitivity analysis of a moist 1D Eulerian cloud model using automatic differentiation, Mon. Weather Rev., 127, 2180-2196.

Peters, L., C. Berkowitz, G. CARMichael, R. EAster, G. Fairweather, S. Ghan, J. Hales, R. Leung, W. PENNEll, F. Potra, R. SAYloR and T. TSANG (1995): The current state and future direction of Eulerian models in simulating the tropospheric chemistry and transport of trace species - A review, Atmos. Environ., 29 (2), 189-222.

PIELKE, R. (1998): The need to assess uncertainty in air quality evaluations, Atmos. Environ., 32, 1467-1468.

RALL, L. (1981): Automatic differentiation - techniques and applications, in Lecture Notes in Computer Science (Springer-Verlag, Berlin), vol. 120.

Saltelli, A., K. Chan and E. Scott (2000): Sensitivity Analysis (John Wiley \& Sons), pp. 475.

Silibello, C., G. Calori, G. Brusasca, G. Catenacci and G. FINZI (1998): Application of a photochemical grid model to Milan metropolitan area, Atmos. Environ., 32, 2025-2038.

Xue, M., K.K. Droegemeier and V. Wong (2000): The Advanced Regional Prediction System (ARPS) - A multiscale nonhydrostatic atmospheric simulation and prediction tool. Part I: Model dynamics and verification, Meteorol. Atmos. Phys., 75, 161-193.

Ziomas, I., P. TZOUMAKA, D. BALIS, D. Melas, C. ZeREFos and O. Klemm (1998a): Ozone episodes in Athens, Greece. A modelling approach using data from the MEDCAPHOT-TRACE, Atmos. Environ., 32, 2313-2321. 